\title{
Star Wars (1977): back and forth in time and space
}

Book or Report Section

Accepted Version

Bignell, J. (2010) Star Wars (1977): back and forth in time and space. In: Brown, T. and Walters, J. (eds.) Film moments: criticism, history, theory. British Film Institute and Palgrave, London, UK, pp. 111-115. ISBN 9781844573363 Available at https://centaur.reading.ac.uk/17668/

It is advisable to refer to the publisher's version if you intend to cite from the work. See Guidance on citing.

Publisher: British Film Institute and Palgrave

All outputs in CentAUR are protected by Intellectual Property Rights law, including copyright law. Copyright and IPR is retained by the creators or other copyright holders. Terms and conditions for use of this material are defined in the End User Agreement.

\section{www.reading.ac.uk/centaur}

\section{CentAUR}

Central Archive at the University of Reading

Reading's research outputs online 
Star Wars: Back and Forth in Time and Space

Jonathan Bignell

In the opening moments of the 'original' Star $\operatorname{Wars}^{1}{ }^{1}$ time and space are being moulded flexibly, and in ways that point both back and forward in film history. By studying the spatial and temporal shifting within the first few shots in detail, this chapter shows how the filmmakers' choices open up questions about what kind of film this is. Not all of those questions have straightforward answers, because the film offers overlapping and sometimes divergent ways of understanding its fictional world.

Where are we, and when?

The film begins with $20^{\text {th }}$ Century Fox studios' logo, accompanied by a fanfare first used in the 1930s. The fanfare is in the same musical key as the loud orchestral burst that begins John Williams's musical score for the film, and the fortuitous aural match between them is the first of a series of links and distinctions between past, present and future at a visual and musical level. The opening caption against a black background, 'A long time ago, in a galaxy far, far away ...' sets the film in a distant place and a distant time. At once the phrase signals fairytale storytelling about the past (like 'Once upon a time') and futuristic science fiction ('galaxy'), and its dotted ellipsis tells the audience that a story will follow. The black background matches the mainly black star field that subsequently appears, on which the film's title logo briefly occupies the centre of the frame before rapidly shrinking into the distance. Yellow text in upper and lower case lettering begins 
to scroll upward into the frame, moving back and diminishing into an infinite distance.

Since the text refers to previous events it is clearly one among many chapters of the story, and introduces the idea that just one part of a huge saga about the past is being told. ${ }^{2}$ The slow movement and left- and right-justification of the text connote the orderliness of this fictional world, like the conventional narrative patterning of a fairytale, despite the violent conflict between Rebels and Empire that the text describes. The musical score uses the full resources of a classical orchestra, and its theme is played primarily by brass instruments. Like the language of the captions, it refers backward in time. Its classical symphonic music follows the conventions of an opera overture in introducing motifs and musical themes that will structure the film and identify characters. The now-famous sequence of brass notes, rising, falling back and then rising again in a triumphant major key, will be used later whenever Luke Skywalker is on screen (and each major character has a theme particular to him or her). The upward reaching of the brass notes matches the hope for freedom that the crawl text outlines, yet its falling back also conveys the reversals of fortune and struggle that the Rebels undergo. The main musical motif resolves, to arrive at a confident restatement of its opening note, one octave higher than when it began. While the crawl text announces the prospect of restoring 'freedom to the galaxy' but leaves the rest of the film to show whether that can be achieved, the musical opening's brass fanfare, major key and rising sequence of notes promise heroic resolution.

In these first moments, placement in space and time are being subverted. A legendary or mythical story about the past is set in a science-fictional futuristic world, and this first Star Wars film appears surprisingly to begin in the middle of that story. 
Spatially, the first brief caption seemed superimposed on a two-dimensional background, while the title logo and crawling text introduce a new dimension of depth. Because the crawl text is in the present tense, it seems to be generated within the present of the story, within the three-dimensional blackness of outer space through which it moves, and thus exists in a different time from 'A long time ago'. The crawl text makes a link between Star Wars and the science fiction film serials of the 1930s such as Flash Gordon or Buck Rogers that were structured as episodic narratives in weekly instalments, and here too, the text's function is ambivalent. It announces that the film has begun and provides information that sets what follows in a definite context, but its allusions to other films from the past and to traditions of science fiction storytelling draw attention to the knowledge the audience bring into the cinema with them from outside. In the same way, the orchestral score draws on the familiar instrumentation and structure of classical music, and the ways it was adapted for film music in the heyday of Hollywood cinema. The music belongs to the past, but matches the tropes of heroic adventure with which the crawl text has shaped this futuristic story. Standing at the border of the film, the text and the opening music are both inside and outside the film, just as the story is ambivalently historical and futuristic. ${ }^{3}$ 


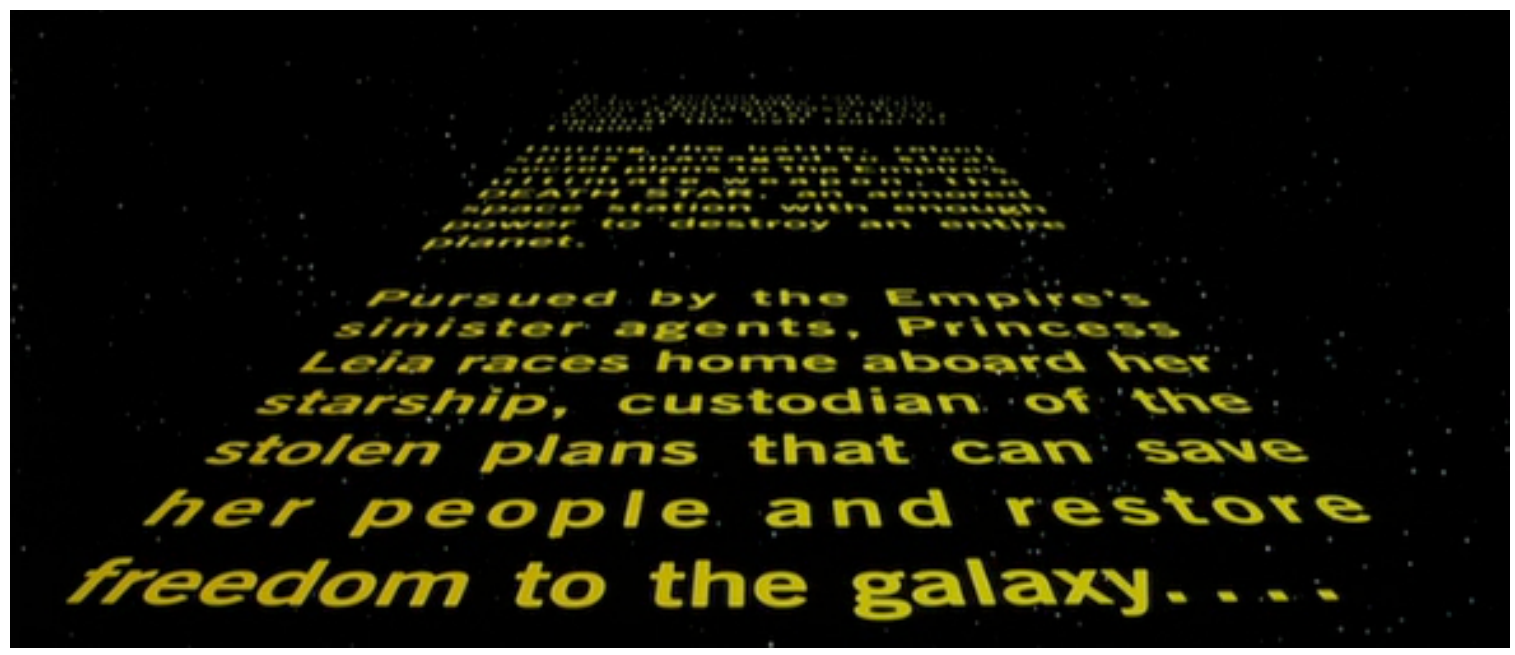

The spatial scale of the opening moments of Star Wars announces a new epoch in cinema technology. The crawl text does not fill the sides of the frame, which makes the sheer horizontal extent of the widescreen frame clear by leaving some of it empty. Shot in a 70mm format (one among many kinds of film stock that sought to express cinema's visual superiority over television), the film is designed to be seen in the cinema on a large screen. In this sense, Star Wars advertises cinema itself as a visual experience, supported by extensive orchestral music that can dominate the auditorium. Following the crawl text, a marked camera movement opens up the fictional space by panning downwards to show two moons and the edge of a planet. The main musical theme dies away, replaced by a quiet and hesitant tinkling that suggests the emptiness of space. Although in itself the camera movement might be somewhat disorienting because it suddenly changes the orientation of point of view, its purpose is to make location more specific in contrast to the generality of distant stars, since the distant moons provide a sense of scale to the space. Once the camera movement is completed, the frame is stabilised again for a spectacular use of new effects techniques when two spaceships fly over the camera. By 
having the first ship fly into a stable frame, the viewer is able to contemplate the details of its shape as they are gradually revealed, and to understand its motion. This sequence is clearly part of the story, rather than an interruption like the 'beauty shots' of the USS Enterprise that lovingly circle the spacecraft early in the first Star Trek film, for instance. Star Wars can have it both ways, introducing the narrative trope of pursuit and also showing off the detailed miniature. As laser beams confirm the spatial alignment of the scene, a second, much larger spacecraft flies over the camera. It gradually fills the screen's upper sector, coming much closer to the camera and offering further fascination with the detail and scale of the image. Star Wars' special effects are important to the film's revival of science fiction as a film genre because of its huge audiences and profitability. The director George Lucas founded the special effects company Industrial Light and Magic (ILM) as part of the Star Wars project, and it pioneered the use of 'motion control' (cameras controlled by computers) for shooting complex models in apparent movement. Sequels have used increasing amounts of computer effects and animation, but some of the 1977 film's pleasure is based on the knowledge that miniatures were fabricated for it, and several international touring exhibitions have been mounted to showcase the models and the techniques used to film them. While the film uses state-of-the-art techniques to engender belief in its fictional world, it capitalises on the knowledge that its world is artificial and painstakingly constructed.

The film continues a tradition of making science-fictional worlds plausible by following the physical conventions that audiences expect. ${ }^{4}$ The stability of the frame while the spacecraft fly into it more easily respects conventions of perspective and composition than a moving shot. The visual field is harmoniously composed, with the 
trajectories of the laser beams and spaceships running along the centre and diagonals of the frame according to classical conventions of painting, and later of cinema. Pointing towards the planet's rim, the two spacecraft and the laser blasts' trajectories are roughly parallel, providing a virtual vanishing point in the centre of the frame that supports the perspectival coherence of a three-dimensional space rendered on a two-dimensional screen. Strategies to make the action comprehensible according to established expectations continue within the shot, since the hulls of the two spacecraft appear to be made of metal plates, with rivet joints visible, and each has protruding turrets, ductwork and ancillary machinery breaking their smooth surfaces. Both spacecraft's engines and weapons make loud sounds even though sound-waves cannot travel in the vacuum of space, and the huge exhaust cones of the Empire's ship are blackened. Lucas commented, 'What is required for true credibility is a used future. ${ }^{, 5}$ Audiences were already familiar with space travel from television coverage of the Apollo missions, in which space capsules accumulated detritus such as used food containers and were discoloured by rocket exhaust. Lucas continued, 'although Star Wars has no points of reference to Earth time or space, with which we are familiar, and it is not about the future but some galactic past or some extra-temporal present, it is a decidedly inhabited and used place where the hardware is taken for granted'. His comments show how spatial perspective, point of view and the verisimilitude of the models joined together elements from diverse genres, times and fictional spaces: 'We were trying to get a cohesive reality. But since the film is a fairy tale, I still wanted it to have an ethereal quality, yet be well composed and, also, have an alien look'. 
This technique of assemblage or bricolage is potentially confusing, so patterned motifs of big and small, powerful and powerless, black and white, mechanical and mystical, are used to give order and structure to the narrative. The crawl text has already informed the audience that a Rebel ship is fleeing from the oppressive Empire, and the opening spacecraft sequence maps this positive connotation of smallness and relative powerlessness onto the smaller spacecraft attacked by a much larger one. Music is also used to map the significance of the sequence, for as the first ship appears the score introduces a musical motif for the Rebels. But it is gradually overridden by rhythmic bass pulses and the start of a military motif played on horns and strings, representing the Empire, as the gigantic Imperial cruiser dominates the visual field. The next scene cuts from space to inside the Rebel ship, where two robots move along a corridor towards the camera. Familiar conventions again enfold alien subjects to make them comprehensible, since despite being in space, gravity holds the robots in place and distinctions between walls, floor and ceiling match those of Earthbound buildings. At this point, with the appearance of the human-like figure of $\mathrm{C} 3 \mathrm{PO}$, the narrative begins to link the grand scale of epic political and military conflict with the actions and emotions of particular characters who are caught up in it. 


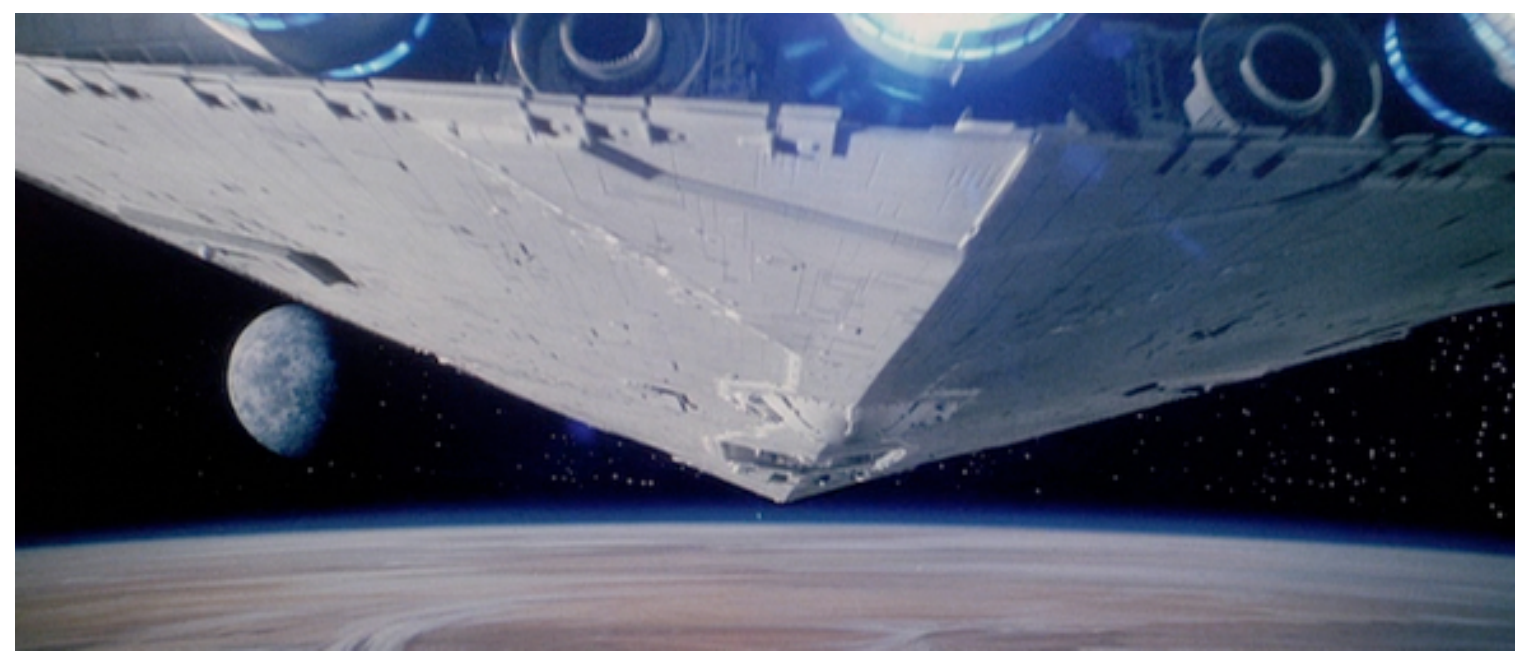

You have seen this before

An analysis of the film's opening moments can show how Star Wars offers its audiences ways to make sense of its narrative. These include the opening captions' references to fairytales, to epic conflicts between an evil Empire and freedom-loving Rebels, and to the cinema serials of the 1930s. Visually, the film makes its spaceships look functional, and subject to the wear and tear of everyday use. Basic conventions like perspective, gravity and a sense of up and down make outer space comprehensible, and the film introduces characters who speak English. The music of the opening moments uses a full orchestra, and adopts the conventions of Hollywood film music based on late-nineteenth century forms such as those of Richard Wagner, mixed with more recent musical styles, especially that of Aaron Copeland who reworked a European tradition for nationalistic American ends. ${ }^{6}$ The emotional tone of the musical motifs and their connection with specific characters and narrative tropes guide the spectator's relationship to the action. These interlocking, overlapping patterns and systems continue as the film proceeds, and 
are further developed and built upon. Fredric Jameson called Star Wars a 'nostalgia film' because it deploys conventions, motifs and clichés deriving from different historical periods and media, but displaces them from their contexts and collapses them together. ${ }^{7}$ Star Wars' references to popular culture beyond the opening moments include the Western, especially The Searchers where the hero must leave his home to rescue a woman captured by the Indians, ${ }^{8}$ and sea adventure where outlaw pirates use trickery and courage to defeat naval authority. Star Wars is also a medieval quest, with the Jedi Knights defending a legacy of mystical and chivalric values against its perversion in the service of the Empire, ${ }^{9}$ and a comedy film centring on the adventures of a duo of 'little guys', C3PO and R2D2 who wrangle at the edges of the epic story. It is a coming-of-age story where Luke Skywalker leaves his rural home to grow up and realise his true identity, a Cold War thriller dramatising the struggle of the Rebel Alliance against the evil Empire, and a Second World War film with aerial dogfighting and a commando raid against the Death Star.

There are some ideological notions that most of these sources share, such as the conventionally male hero and a woman in need of rescue, the valuation of youth over age, and a moral structure that leads to the expectation of a happy ending that brings order to a society and confirms the ennoblement of the protagonist. But they are also ambivalent about the home to which the hero cannot return, his implication in violence and his close association with the antagonist. Star Wars is not simply an affirmation of the myths it reworks, but also offers a reconsideration of them. The film offers competing interpretations that can co-exist, and thus addresses diverse audiences. The opening crawl text presents it as a conservative story about gung-ho American individuals combating 
oppressive colonial and militaristic imperialists, and thus draws on the positive connotations of rebellion that have been used to underpin myths about the founding of the USA and the US's support for other freedom-fighters around the world. But it is also a postmodern story about the creative and liberating possibilities for open-minded alliances that look to the future, bringing different races and cultures together. ${ }^{10}$ This reading of the film was reinforced by Lucas's addition of the title 'Episode IV: A New Hope' to some cinema versions of the film in 1981, subsequently retained in later versions. The presence of Chewbacca, a non-human character, and two robots among the hero team, seems calculated to demonstrate the inclusion of difference. The film is both a Modern 'grand narrative' that believes in progress, freedom and heroism, and a postmodern bricolage that celebrates diversity, critiques mythical archetypes and is one episode in a story that cannot arrive at a satisfactory closure.

Star Wars has been called the first blockbuster film, and the opening moments discussed here have been cited as the announcement of a new kind of gigantism and spectacle in US cinema. ${ }^{11}$ Its visual scale is matched by the film's sound. The film was designed for multi-track stereo loudspeakers, so that the roar of the Imperial spacecraft in the opening scene would match the visual impact of the widescreen image. The notion of the blockbuster is not concerned exclusively with the film itself, however, since much of Star Wars' cultural impact and financial profit came from associated products. Its props, characters and narrative forms are 'toyetic' (a good basis for toys) in that there are visually and narratively distinctive characters who can become action figures, a range of spacecraft that can become toys, and a strong, simple narrative that can mutate into games, comics and further film and television products. Toy licensing from the 1977 film 
was worth $\$ 500$ million for the Hasbro and Galoob companies who manufactured the toys, and franchises to associate products (such as tee-shirts, lunchboxes and pyjamas) with its characters were worth $\$ 1.5$ billion per year. ${ }^{12}$ Star Wars entered popular culture not only because many people saw the film, but also because its imagery and themes spread more widely. For example, President Ronald Reagan's missile defence initiative to combat nuclear attack from 'the evil empire' of the Soviet Union was nicknamed 'Star Wars' by opponents who regarded it as a fantasy that would never work, and key lines like 'May the Force be with you' became staples of everyday speech.

For these reasons, it is almost impossible to regard the opening moments of Star Wars as a sequence that can be freshly interpreted in its own terms. Rather it becomes necessary to make a special effort to stop the flow of these few shots and examine them in detail, to see how they open up some of the many strands of meaning and reference that are built upon them later in the film, and that have been extended and changed by the related texts that appeared subsequently. Seeing the film now, after it has been bracketed by prequels, sequels, merchandise and computer games, further destabilises its meanings. One of these problems concerns which version of the film might be the 'original' Star Wars. Only some US cinemas were equipped to screen the film in $70 \mathrm{~mm}$ using its full Dolby stereo sound in 1977 , so some audiences saw a $35 \mathrm{~mm}$ version or a $70 \mathrm{~mm}$ version with different sound. Subsequently, video, laserdisc and DVD versions of the film were released for home viewing and television broadcast, again with differences between them. George Lucas digitally remastered the film, adding new CGI effects, in 1997, claiming that this was the version he would have made originally if technology had allowed. A close analysis of the film's opening moments begins to ask the question, what 
is Star Wars?, and further consideration of the rest of the film and its cultural history makes that question more insistent and harder to answer.

${ }^{1}$ This chapter discusses the original theatrical release of 1977, but questions about the status of this version of the film as the 'original' are debated later in the chapter.

${ }^{2}$ Sean Cubitt, 'Preliminaries for a Taxonomy and Rhetoric of On-Screen Writing', in Jonathan Bignell (ed.), Writing and Cinema (Harlow: Longman, 1999), pp.63-5.

${ }^{3}$ Tom Conley, Film Hieroglyphs: Ruptures in Classical Cinema (Minneapolis: University of Minnesota Press, 1991).

${ }^{4}$ Piers D. Britton, 'Design for Screen SF', in Mark Bould, Andrew M. Butler, Adam Roberts and Sherryl Vint (eds), The Routledge Companion to Science Fiction (London and New York: Routledge, 2009), p.343.

${ }^{5}$ Anon., Introduction to 'Behind the scenes of Star Wars', American Cinematographer (July 1977), accessed at http://www.theasc.com/magazine/starwars/index.html, June 2009.

${ }^{6}$ Ken McLeod, 'Music', in Mark Bould, Andrew M. Butler, Adam Roberts and Sherryl Vint (eds), The Routledge Companion to Science Fiction (London and New York: Routledge, 2009), p.396.

${ }^{7}$ Fredric Jameson, 'Postmodernism, or the Cultural Logic of Late Capitalism', New Left Review 146 (1984), 53-92.

${ }^{8}$ John Ford's The Searchers was a reference point for many young directors and screenwriters of the 1970s, and its motifs were reworked in films including Mean Streets (Scorsese 1973), Taxi Driver (Scorsese 1976) and The Deerhunter (Cimino 1978). See Douglas Pye, 'Writing and Reputation: The Searchers, 1956-1976', in Jonathan Bignell (ed.), Writing and Cinema (Harlow: Longman, 1999), p.206.

${ }^{9}$ David Williams, 'Medieval Movies' in Yearbook of English Studies vol.20 (1990), pp.132.

${ }^{10}$ Will Brooker, 'New Hope: The postmodern project of Star Wars' in Peter Brooker and Will Brooker (eds), Postmodern After-Images: A Reader in Film, Television and Video (London: Arnold 1997), pp.101-12.

${ }^{11}$ Scott Bukatman, 'Zooming Out: The End of Offscreen Space, in J. Lewis (ed.), The New American Cinema (Durham, NC: Duke University Press, 1998), pp.248-72.

${ }^{12}$ Graham Dawson, 'War Toys', in Gary Day (ed.), Readings in Popular Culture: Trivial Pursuits? (Basingstoke: Macmillan, 1989), pp.104-5. 